\title{
Controlling outsourced management accounting to build legitimacy
}

\author{
Sinikka Lepistö \\ Department of Accounting, Oulu Business School, \\ University of Oulu, Finland \\ Justyna Dobroszek \\ Faculty of Management, University of Lodz, Lodz, Poland \\ Lauri Lepistö \\ Turku School of Economics, Pori Unit, University of Turku, \\ Turku, Finland, and \\ Ewelina Zarzycka \\ Faculty of Management, University of Lodz, Lodz, Poland
}

Controlling

outsourced

management

Received 20 May 2019 Revised 30 October 2019 20 February 2020 Accepted 23 March 2020

\begin{abstract}
Purpose - This paper aims to explore controls within an inter-organisational relationship involving outsourced management accounting services from the contractor's perspective.

Design/methodology/approach - Qualitative data from within the relationship are analysed in a legitimacy-theory framework, illustrating how controls within the relationship are intended to build the contractor's legitimacy and what kinds of implications the controls have in relation to conflicts between interests inherent in the relationship.

Findings - The legitimacy perspective clarifies that while controls are aimed at ensuring efficiency for the client, they may also provide symbolic displays of the appropriateness of the contractor's actions both at an inter-organisational level for the client and at an individual level for the contractor's employees. While the contractor intends to build legitimacy with the client by demonstrating utility in the form of efficiency, the process also gives the client influence and allows the disposition in terms of shared values to be demonstrated. However, this process has some negative consequences for the contractor's employees as it is insufficient for serving the boundary-spanning employees' interests connected with the nature of their work. Hence, the same controls need to yield benefits and fair outcomes for employees. The controls simultaneously foster interconnections that contribute to permanence and formalise the outsourcing of complex services, thereby
\end{abstract}

(C) Sinikka Lepistö, Justyna Dobroszek, Lauri Lepistö and Ewelina Zarzycka. Published by Emerald Publishing Limited. This article is published under the Creative Commons Attribution (CC BY 4.0) licence. Anyone may reproduce, distribute, translate and create derivative works of this article (for both commercial and non-commercial purposes), subject to full attribution to the original publication and authors. The full terms of this licence may be seen at http://creativecommons.org/licences/by/4.0/ legalcode

The authors are grateful to the anonymous reviewers, Allan Hansen, Martin Carlsson-Wall, Lisa Jack and Jari Paranko for their suggestions and comments on previous drafts of this paper. The authors also acknowledge with gratitude the comments of the participants of the 10th EIASM Conference on New Directions in Management Accounting in Brussels (2016). In addition, the corresponding author gratefully acknowledges financial support from the Foundation for Economic Education and the Marcus Wallenberg Foundation.

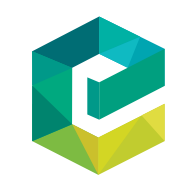

Qualitative Research in Accounting \& Management Vol. 17 No. 3,2020 pp. $435-463$ Emerald Publishing Limited 1176-6093 DOI 10.1108/QRAM-05-2019-0062 
QRAM 17,3

rendering such processes comprehensible and transferable to other settings, which can be seen to serve the contractor's continuity interests.

Originality/value - The paper contributes to academic research by illustrating how controls within interorganisational relationships not only steer boundary-spanners' work to conform to a client's needs but may also help to build legitimacy via symbolic properties in the presence of conflicting interests at both an interorganisational and individual level. It specifically highlights the important role of boundary-spanners lower in the organisational structure, who both affect and are influenced by the intentions to build legitimacy with the client.

Keywords Outsourcing, Legitimacy, Management accounting, Inter-organisational control

Paper type Research paper

\section{Introduction}

Globalisation and fierce competition have turned various forms of inter-organisational relationships into important tools for success, with scholars, accordingly, directing attention to what kinds of controls may be used to align the possibly conflicting interests inherent in such relationships (Kraus and Lind, 2007; Mouritsen and Thrane, 2006; Thrane, 2007; Vélez et al., 2008). A significant amount of research has focussed on conflicting interests between partners, and specifically on controls to minimise transaction costs and forestall opportunistic behaviour by the other party (Dekker, 2004; Langfield-Smith and Smith, 2003; Nicholson et al., 2006; Van der Meer-Kooistra and Vosselman, 2000). Scholars have also acknowledged that the structure of any inter-organisational relationship is ambiguous and its conflicting interests reside at several levels, between and within the partners. This phenomenon between organisational units or other groups exists because people hold divergent views on how to fulfil economic interests and reach organisational business objectives (Carlsson-Wall et al., 2011; Coad and Cullen, 2006; Kraus and Strömsten, 2016; Thrane and Hald, 2006). While some view the interests in terms of cost-efficiency, this perspective may come into conflict with the interests of those more focussed on customerorientation (Coad and Cullen, 2006) or on developing the product rather than minimising costs (Kraus and Strömsten, 2016; Mouritsen et al., 2001; Seal et al., 2004). Accordingly, these studies attest that how business objectives (economic interests) are pursued in an interorganisational relationship is far from self-evident, as a conflict of interests arises from the differences in social beliefs pertaining to what constitutes (economically) appropriate action.

Earlier research demonstrates also that employees constitutive to the relationship have their own stakes in it (Coad and Cullen, 2006). Specifically, boundary-spanners, working between the co-operating organisations to manage the relationship, need to pursue a mixture of goals: they must safeguard their own interests such that their career does not suffer if they pursue the best of the relationship (Dekker, 2016). While extant research has shown that boundary-spanners may have a pivotal role in creating and developing conflicting interests in their use of controls (Zahir-ul-Hassan et al., 2016), the definition of "boundaryspanners" has been restricted to people who can use controls from a managerial position. Though scholars have examined how controls shape the relationship by determining the boundaries of the partner organisations (Mouritsen et al., 2001; Thrane and Hald, 2006) and how boundary-spanners may be active in this process (Zahir-ul-Hassan et al., 2016), no research has heretofore explored the role of boundary-spanners lower in the organisations. Subject to controls themselves, these boundary-spanners balance the partners' possibly conflicting interests and decide between them, with their own interests at stake (Dekker, 2016). In so doing, they are affected by the partners' relationship and controls within it, simultaneously affecting that relationship through their work. 
Differences in social beliefs about appropriate behaviour point to one way of managing conflicts of interests through influencing perceptions of appropriateness (Kumar and Das, 2007). This renders social approval (legitimacy) among the various interest groups crucial to inter-organisational relationships (Human and Provan, 2000; Scapens and Varoutsa, 2010). While we know that controls can be used to build legitimacy, their role in legitimacybuilding in inter-organisational relationships has not been explored (Scapens and Varoutsa, 2010). The matter is anything but trivial, for numerous controls are in operation, acting at various levels of the relationship and shaping it. Firstly, inter-organisational controls shape the relationship and may be used to build legitimacy between the partners at the interorganisational level. Secondly, controls that steer the behaviour of people working for the partners operate between an inter-organisational and individual level (Coad and Cullen, 2006; Cuganesan, 2006; Mouritsen et al., 2001), possibly having consequences for these workers (boundary-spanners, etc.) and influencing the legitimacy that they confer on the partners. Accordingly, all these controls may have consequences both between and within the organisations.

To explore controls within inter-organisational relationships in a manner acknowledging the various levels at which controls act and that legitimacy within the relationship may be built, we studied a relationship involving outsourced management accounting services between a client and a contractor, focussing on the contractor's perspective. Such a relationship offers a fruitful setting to study legitimacy-building and the effects of it on multiple levels, as the work pertains to client-specific management accounting information: every employee of the contractor is a boundary-spanner communicating with client representatives. At the same time, the contractor strives to meet the requirements of the client, yet also seeks to ensure the continuity of its own operations. A legitimacy perspective informed our analysis by highlighting that satisfying multiple interests in a lasting manner is a matter of not only short-term efficiency but also of gaining social approval among several interest groups that grant legitimacy both at an inter-organisational and individual level (Deegan, 2006; Moll and Hoque, 2011; Seal et al., 2004). We developed a picture of the conflicts of interests affecting the partners and boundary-spanners in the outsourcing relationship, which created a need for the contractor to build legitimacy to satisfy its own organisational interests, and we analysed the place of controls within the interorganisational relationship in this picture. The analysis aimed to answer the following question:

Q1. How may controls within an inter-organisational relationship for outsourced management accounting services intended to build legitimacy with the client(s) have consequences on the contractor's boundary-spanning employees and the legitimacy they grant to the contractor?

An in-depth examination of precisely such a relationship from the contractor's perspective contributes to our understanding by providing clear underpinnings for our thinking about controls within inter-organisational relationships and how those controls may affect and incorporate the interests of several parties: this paper specifically examines those of the client, the contractor and the contractor's boundary-spanning employees (Dekker, 2016). The contribution, thus, ties in with the legitimacy perspective informing our analysis. Current understanding of inter-organisational controls is advanced by addressing the symbolic aspects of controls that demonstrate legitimacy within inter-organisational relationships rather than merely the controls' technical properties serving the client's best interest or contributing to clashes of interests (Nicholson et al., 2006; Mouritsen et al., 2001; Seal et al., 2004). These symbolic properties assist in understanding how, for instance, organisational
Controlling outsourced management 
QRAM 17,3 boundaries may be extended so as to encourage the transfer of more complex services to the contractor, which advances the contractor's interests (Mouritsen and Thrane, 2006; Mouritsen et al., 2001). The legitimacy perspective underscores how these controls may help to build legitimacy in multiple ways, as they conform to various concepts of appropriateness held by particular stakeholders/groups (Håkansson and Lind, 2004), and when the conformance is communicated. Finally, while lower-level employees' interests have been mentioned in previous works, we delved more deeply into how these people are affected by controls within inter-organisational relationships, specifically with regard to their work's boundary-spanning nature (Coad and Cullen, 2006; Dekker, 2016; Van der Meer-Kooistra and Vosselman, 2000). These workers influence the legitimacy between the partners, and legitimacy must be cultivated by conformance and communication with the help of controls among this important group at the same time.

Important groundwork is laid in Section 2, presenting the theoretical and conceptual direction for the study and discussing the relevant literature on controls in interorganisational relationships in conditions of conflicting interests, alongside the legitimacy perspective. Then, Section 3 describes the research design and Section 4 presents an analysis of the empirical findings, with concrete examples from the data. These findings and their implications are discussed in Section 5, with the article then rounded out by concluding remarks.

\section{Theoretical and conceptual guidelines}

2.1 Control within inter-organisational relationships in the presence of conflicting interests Inter-organisational controls consist of policies and procedures that align possibly conflicting interests of the co-operating partners with the inter-organisational relationship (Kraus and Lind, 2007; Mouritsen and Thrane, 2006; Thrane, 2007; Vélez et al., 2008). Importantly, conflicting interests are not found only between partners, so the controls do not merely prevent the partners' opportunistic behaviour, and thereby minimise transaction costs (Dekker, 2004; Langfield-Smith and Smith, 2003; Nicholson et al., 2006; Speklé, 2001; Van der Meer-Kooistra and Vosselman, 2000). On the contrary, inter-organisational relationships involve complex networks in which conflicting interests exist at several levels. The conflict may be manifested between subunits of an organisation, for example, departments (Carlsson-Wall et al., 2016; Cuganesan, 2006; Håkansson and Lind, 2004; Kraus and Strömsten, 2016). In parallel, interests related to cost-efficiency come into collision with other interests (Carlsson-Wall et al., 2011), such as engineering goals (Mouritsen et al., 2001; Seal et al., 2004), interests in customer-orientation (Coad and Cullen, 2006) and employees' interests (Coad and Cullen, 2006).

As Coad and Cullen's (2006) research indicates, a conflict of interest may also arise between employees and the inter-organisational relationship. The boundary-spanners, working between the partner entities as they do, manage the relationship in accordance with their need to achieve and maintain balance, on the one hand, between the two partners in terms of interests and, on the other hand, between those higher-level goals and the protection of their own interests, for example, in career development (Dekker, 2016). When the inter-organisational relationship involves outsourcing, the process of centralising support services and separating them from the outsourcer organisation has particular consequences for the employees. Centralised services entail repetitive work that leads to a narrowing in the expertise of workers such as accountants within outsourcing relationships (Nicholson and Aman, 2012; Seal and Herbert, 2013). Thus, the conflicts of interests tie in with differences in individuals' and organisations' identities: what individuals or organisation members perceive, feel and think about themselves or their organisations 
(Thrane and Hald, 2006). Accordingly, the parties may differ markedly in their perceptions of economic interests, how to reach business objectives and what actions are appropriate for themselves.

Similar to conflicting interests, controls within inter-organisational relationships operate at several levels. Alongside inter-organisational controls, there are more intra-organisational ones designed to steer the behaviour of employees within the partner entities. These controls influence each other (Coad and Cullen, 2006; Håkansson and Lind, 2004; Mouritsen et al., 2001; Seal et al., 2004; Thrane and Hald, 2006) and internal work practices (Carlsson-Wall et al., 2011). Also, intra- and inter-organisational controls may co-evolve (Cuganesan, 2006). Accordingly, the controls actually shape the inter-organisational relationship and delineate the organisations' boundaries (Mouritsen et al., 2001; Thrane and Hald, 2006). Again, while boundary-spanners within the layers of management may clearly shape the relationship via controls (Zahir-ul-Hassan et al., 2016), much less is known about boundary-spanners at lower levels. In any case, they are subject to inter- and intra-organisational controls alike, all of which are in play to align the conflicting interests.

As the discussion above attests, it is important to consider how the inter-organisational relationship develops, which is often associated with the controls used and their interrelations (Carlsson-Wall et al., 2011; Kraus and Lind, 2007; Zahir-ul-Hassan et al., 2016). In a prime example, ensuring efficiency via actions such as cost-cutting and corresponding controls may be in the client's interest, but those actions have effects on both the contractor and its employees, whose interests are at stake. As the appropriate way to reach business objectives is not self-evident (i.e. several views of how to act appropriately exist in parallel), perceptions and the associated social approval, in the form of legitimacy, are rendered important at many levels in the inter-organisational relationship (Kraus and Strömsten, 2016; Kumar and Andersen, 2000). From the contractor's perspective, we explore two levels at which the controls function and may be used to build legitimacy. While social approval is important at the inter-organisational level between the partners, at the same time, boundaryspanners are subject to controls within the relationship that both develop and grant legitimacy to the employing partner. They work inter-organisationally, between the partners, but their interests may differ somewhat from the organisations'. Therefore, boundary-spanners' work steered by controls, in turn, affects legitimacy. In this connection, it may be difficult to disentangle whether a certain control is inter- vs intra-organisational, on account of the interrelationships between the two, so we refer instead to controls within an inter-organisational relationship. Next, we elaborate on how work on legitimacy informed our analysis.

\subsection{Legitimacy and controls in inter-organisational velationships}

Legitimacy may be defined as "a generalised perception or assumption that the actions of an entity are desirable, proper or appropriate within some socially constructed system of norms, values, beliefs and definitions" (Suchman, 1995, p. 574). Scholars have often focussed on how to get external stakeholders to deem an inter-organisational relationship legitimate (Kumar and Andersen, 2000; Scapens and Varoutsa, 2010), yet internal stakeholders too are important legitimating audiences for any organisation (Moll and Hoque, 2011). Gaining legitimacy relationship-internally from the partner organisations in the early stages of an inter-organisational relationship may be even more important for the continuity of that relationship than building external legitimacy is (Human and Provan, 2000). Another important internal stakeholder is employees working for the organisation (Moll and Hoque, 2011). If there are career concerns as discussed above, then demonstrating that one's organisation is a suitable workplace becomes necessary for attracting and retaining 
QRAM 17,3

competent workers. In any case, the existence of multiple legitimating stakeholders entails a multiplicity of socially created interests in definitions of appropriateness. Separate interests are often in conflict, as are activities aimed at legitimisation with respect to each of them, although not always fundamentally so much as dictated by specific situations (CarlssonWall et al., 2016; Schäffer et al., 2015).

Legitimacy may be seen from several perspectives. A managerial perspective focusses on the ways in which organisations knowingly and actively use symbols as instruments to manage perceptions and garner societal support (Oliver, 1991; Suchman, 1995). On the other hand, one can take the perspective of society at large, looking at institutional effects within the organisation in a way that presumes a more passive adaptation (Deephouse and Suchman, 2008). In fact, these perspectives are two sides of a single coin: to be able to employ symbols knowingly, one must be aware of the institutional expectations under which one is operating (Scapens and Macintosh, 1996). Against this backdrop, although the present paper explores a particular inter-organisational relationship in which the contractor explains its intentions to build legitimacy with the client (and employees) with the help of controls, the paper also accounts for how these intentions are related to the more general social demands in outsourcing.

The concept of legitimacy actually helps shed light on the pressures for seeking social approval that are present alongside economic elements and intertwined with them (Scapens and Varoutsa, 2010). Although some institutional literature portrays social approval and economic concerns as somewhat incompatible pressures, leading to decoupling (CarlssonWall et al., 2016; Meyer and Rowan, 1977), they are not inherently mutually contradictory. Firstly, both demonstrating economic efficiency and using symbols in line with socially appropriated ways of working affect perceptions and thereby build legitimacy (Meyer and Rowan, 1977). Secondly, while legitimacy may be a way to reach economic and technical goals (Dacin et al., 2007), economic efficiency remains largely socially defined (Meyer and Rowan, 1977), as can be manifested in disparate views on economically appropriate actions. For example, cost savings may become an institutionalised myth contributing to the legitimacy of outsourced accounting (Deephouse and Suchman, 2008; Hyvönen et al., 2012; Scapens and Varoutsa, 2010), with efficiency metrics, therefore, displaying symbolic properties articulating the legitimacy of the actions taken. As legitimacy may be episodic or continual, demonstrating cost savings and cost-efficiency brings only a temporary state of legitimacy: the organisation may achieve the required cost cuts in one accounting period but not another. In contrast, legitimacy arising from adapting to other social norms is of a more long-term nature, as, in contrast to socially approved outcomes, socially approved ways of acting are perceived as producing more consistent socially approved outcomes (Suchman, 1995).

Our analysis benefits from Suchman's (1995) framework of legitimacy, which is general enough to capture important elements in inter-organisational relationships. It also enables analytically delineating empirically intertwined pragmatic, moral and cognitive dimensions of legitimacy and multiple strategies to build legitimacy (Deephouse and Suchman, 2008; Kumar and Das, 2007), including conformance, selection and manipulation of the environment (O'Dwyer et al., 2011). As we focus on a particular inter-organisational relationship, the selection of the environment has already happened, and the main focus of analysis is, thus, on conformance to the environment, specifically to the stakeholders' interests and manipulation of the environment by altering the perceptions of important stakeholders by clearly communicating this conformance (Kumar and Andersen, 2000). Moreover, Suchman's framework aids in remembering that legitimacy has both episodic (short-term) and continual (long-term) forms. 
Pragmatic legitimacy involves the most immediate stakeholders seeking benefits for themselves (Suchman, 1995). As such legitimacy entails serving self-interested stakeholders, it is most directly linked to boundary-spanners' work in inter-organisational relationships (Dekker, 2016; Kumar and Andersen, 2000). The simplest way to build pragmatic legitimacy is to conform to the demands of an important stakeholder by demonstrating benefits, which are related to the utility exchange between the organisation and stakeholder (Suchman, 1995). Altering perceptions may occur by displaying the benefits via symbols of economic efficiency in outsourced accounting, as defined socially by the client: cost savings, quality

Controlling outsourced management improvements, etc. (Hyvönen et al., 2012; McIvor et al., 2011) with strategic communication (O’Dwyer et al., 2011). While exchange-based legitimacy may be episodic, demonstrating conformance to the interest of stakeholders brings in more lasting elements too: influence aspects, involving the ability to ensure the organisation's responsiveness to stakeholders' larger interests and dispositional attributes such as demonstrating values in common with the stakeholders'. Building these requires an organisation to incorporate stakeholders such as clients into its policy-making structures or to demonstrate stakeholders' values to be its own (Suchman, 1995). Hence, garnering influence legitimacy with a client requires not only meeting that client's needs ( Vosselman, 2002) but also eliminating uncertainties and fostering perceptions that the client is in control (Suchman, 1995). Accordingly, communication is essential for building legitimacy (Kumar and Das, 2007; Suchman, 1995).

Moral legitimacy represents a more enduring, normative form of legitimacy that entails a general positive perception of the organisation and its activities. At its roots, this involves evaluating the rightness of those actions (Kumar and Das, 2007). Temporary positive perceptions may arise from how the actions' consequences are distributed, while the socially accepted procedures of the organisation create more lasting positive impressions (Suchman, 1995). Moreover, moral legitimacy may be episodically related to the personal characteristics or charisma of organisational leaders and more continually to the organisation's structural position in society acknowledged to perform socially accepted work. As outsourced management accounting is a rather new phenomenon, it still may not yet have a structured position as a generally accepted service in society. Moreover, the personal characteristics of leaders are not directly related to controls. Therefore, the focus of our empirical analysis is on the consequential and procedural dimensions of moral legitimacy. Building moral legitimacy thus entails conforming to the ideals of stakeholders and manipulating their perceptions by demonstrating fair actions, responsibility and respect for them (Kumar and Andersen, 2000; Suchman, 1995). This may be especially relevant with regard to employees facing the consequences of centralised services to alter their image of centralised services as an appropriate workplace.

The most long-term and institution-oriented form of legitimacy is cognitive, involving an organisation's attempts to gain more passive support/acceptance as a taken-for-granted part of society (O'Dwyer et al., 2011; Suchman, 1995). Demonstrating the feasibility of something new, such as outsourcing more and more specialised services, falls into this category of building legitimacy, making it important for a provider of such services (O'Dwyer et al., 2011). While being taken for granted represents permanence, it is coupled with attention to a nearer horizon: being integral to society implies comprehensibility: the actions' predictability and plausibility. Building permanence requires presenting simple activities that are perceived as natural and a matter of course, in addition to fostering interconnections with the stakeholders (Suchman, 1995). Conformance is thus related to set models, and interpretations of new practices can be altered by seeking certification and standardising them to formalise operations, all thereby increasing the transactions' predictability and thereby contributing to comprehensibility (O'Dwyer et al., 2011). 
QRAM 17,3

The above discussion indicates that the controls within an inter-organisational relationship are not limited to inter-organisationally assuring cost-efficiency for the client by steering boundary-spanners' individual-level behaviour accordingly; the controls may also provide symbolic displays of appropriateness that build legitimacy by addressing the interests of other stakeholders. Still, the role that controls in inter-organisational relationships play in building legitimacy has been studied little (Scapens and Varoutsa, 2010). Overall, institutional literature addresses primarily how legitimacy may be built via controls, with separate controls often being developed to speak to each specific interest in the search for legitimacy (Schäffer et al., 2015; Siti-Nabiha and Scapens, 2005) and similar findings are discussed in the literature on inter-organisational controls (Håkansson and Lind, 2004). This siloed view of particular controls serving the specific interests of specific stakeholders is specifically problematic in exploring the role of boundary-spanners: separate controls do not assist with the boundary-spanners' work to balance between the partner firms' (and their own) interests.

Clearly, controls may operate in multiple ways of building legitimacy, among diverse stakeholders, giving a contract-limited partner more room to act by directing attention to certain issues, providing key resources and managing perceptions for ensuring continuity (Kraus and Strömsten, 2016; Kumar and Andersen, 2000). As demonstrating utility exchange involves the definition and co-ordination of day-to-day activities, the procedures, evaluation and monitoring are rendered important in these efforts (Kumar and Andersen, 2000) and performance measurement and evaluation may serve as not only technical assurance but also symbolic displays (Merchant and Van der Stede, 2012). Favourable metrics can symbolise the conformance of certain behaviours and expression of values shared with the client or other stakeholders, thereby building dispositional legitimacy, in that these represent foundations for the interactions that build collaboration (Dent, 1991; Meira et al., 2010; Zahir-ul-Hassan et al., 2016). Similarly, formalisation and procedures do not just co-ordinate actions to create exchange legitimacy; they can aid in creating a sense that the operations are standardised, predictable, and straightforward, thus serving comprehensibility. Furthermore, organisational structures provide means of communication and channels of influence that forge perceptions of being in control (Malmi and Brown, 2008; Merchant and Van der Stede, 2012). Finally, when employees' interests are relevant, humanresource management practices, such as training and provision of necessary resources, can demonstrate benefits and fair consequences for the employees concerned, and thus delineate the appropriateness of the workplace for them (Merchant and Van der Stede, 2012).

Table 1 summarises the foregoing discussion of the multiple ways of building legitimacy and of controls' possible part in them.

\section{Research design}

\subsection{Case organisation and setting}

The data for our study came from a client-contractor relationship involving outsourced management accounting services, wherein the client, referred to here as Electro, is a multinational corporation and the contractor, denoted as Pivot, is a department of a large business-process outsourcing (BPO) firm operating worldwide. Pivot uses about 100 people, while the BPO organisation to which Pivot belongs has, in all, more than 13,500 employees. At the delivery centre housing Pivot, in Central Eastern Europe (CEE), there are about 1,300 finance and accounting professionals. Electro, in turn, is one of the world's largest electronics companies, using over 100,000 people globally, and the above-mentioned delivery centre began as an Electro in-house (captive) shared services centre but later was acquired by the multinational BPO organisation. The case offers a particularly fruitful 
Control-related strategies for building different types of legitimacy

Pragmatic legitimacy: utility for stakeholders delivered by the contractor with its activities

Exchange attributes Adapting and conforming to the stakeholders' needs by evaluating and

monitoring adaptation. Communicating the conformance

Specifying and co-ordinating activities with procedures

Influence attributes

Co-opting stakeholders into the decisionmaking structures and

communication, making them feel in control

Dispositional

Adapting and communicating conformity to stakeholders' values by using

attributes

controls in interactions

Moral legitimacy: a general positive normative evaluation ('rightness of actions') of the contractor and its activities (by employees)

Consequences

Conforming to ideals of fair consequences of actions by demonstrating fair outcomes in (HRM) practices

Procedures

Demonstrating responsibility and esteem in the (HRM) procedures

Cognitive legitimacy: Comprehensibility (or "taken-for-grantedness") of the contractor and its operations

Predictability/

plausibility

Formalising and professionalising operations with procedures, presenting

them as simple activities

(Permanence)

Fostering interconnections with the stakeholders in organisational

structures

Popularising and standardising new models, while also seeking certification

Table 1.

Different ways to build legitimacy via controls within interorganisational relationships

setting for exploring legitimacy-building via controls and specifically its effects on the boundary-spanners at lower organisational levels. This is because management accounting is a specialist service whose outsourcing is a rather new development, demanding proof of feasibility (O'Dwyer et al., 2011), especially as Electro is the only client of Pivot (though the latter wishes to widen its customer base). Moreover, the nature of the work pertaining to client-specific information renders all Pivot employees boundary-spanners (Dekker, 2016).

Electro's rationale for undertaking outsourcing of its accounting was in line with more general arguments for outsourcing, involving desires to cut costs and later to improve quality, too. Accordingly, while savings initially came from centralising the services in a country with lower wages, the reporting quality and added business value arising from standardisation and process improvements became additional important factors. Another motivation was an effort to render the management accounting more efficient, starting with several kinds of regular reports that could be made standardised and rule-based. Among these are profit-and-loss reports for the various corporate units but there are also many monthly and quarterly reports addressing the finer details of inventories, delivery times and various types of costs. The outsourcing has changed the role of accountants at Electro they are more like business partners, in parallel to what earlier research has shown (Seal and Herbert, 2013). However, the volume and complexity of the outsourced services have grown over the years of co-operation, as tasks less directly suited to standardisation have been transferred to Pivot too, such as the transfer-pricing process. The latter is handled via a system created by Electro and maintained in co-operation between the two firms. While the main calculations are automated, the system cannot always compute the final prices, so manual work is sometimes needed, which presents unique tasks for Pivot.

Exploring a specific client-contractor relationship and the effects of the controls applied within it that steer the actions and decisions of boundary-spanners in their intentions to build legitimacy with the client calls for precisely the qualitative case-study approach we 
QRAM 17,3

chose for our study (Dekker, 2016; Håkansson and Lind, 2004; Scapens, 1990). Also, this is consistent with the methodological choices in earlier research exploring controls in interorganisational relationships (Carlsson-Wall et al., 2011; Cuganesan, 2006; Mouritsen and Thrane, 2006).

\subsection{The data and analysis}

The primary data sources consist of 23 interviews and an initial meeting that included presentations to the researchers. In co-operation with the director of Pivot, the researchers selected people in various positions, at all levels of the organisation, to be interviewed and also identified the key informants from Electro's side. All interviews and presentations were recorded and transcribed, and the transcripts of interviews conducted in the local language were translated into English. In total, 20 interviews were carried out in Pivot and three in Electro. For some of the interviews, several people were present at the same time, with several people who took part in the initial meeting later being interviewed separately. In all, we engaged in discussion with 29 people, of whom four were from Electro and 25 from Pivot. In total, 12 of the interviewees in Pivot were in a managerial position (director, manager, team manager, process manager) who have the possibility to use at least some controls towards others while being subject to controls themselves. In total, 13 interviewees were purely lower level boundary-spanners who are only subject to various controls but still balancing between various interests. The appendix provides further details on the interviews.

Several other sources supported our analysis. Presentations and textual materials obtained from the firms were used. In addition, one of the researchers was in a partner relationship with Pivot before our project began, as Pivot co-operates with educational institutions to recruit knowledgeable workers and help its employees develop further. Thirdly, we wrote a preliminary research report focusing on the valuable aspects of the outsourced activities in co-operation with the director of Pivot, which confirmed our understanding of the organisation's interests related to social approval. Finally, as the primary data rely heavily on Pivot's perspective, we sought a better understanding of the conflicting interests by considering the four interviews at Electro in conjunction with publicly available material, in a manner similar to the approach of Kraus and Strömsten (2016). Although we had Electro's official approval to collect data from their perspective too, arranging interviews proved extremely difficult in practice. To address this issue, the secondary data comprise five YouTube videos from 2010-2014 (listed in the appendix) in which representatives of Electro discuss the outsourcing of their accounting to the BPO organisation to which Pivot belongs. These videos, which were transcribed for analysis, were useful for strengthening the perspectives obtained via the interviews. They shed particular light on how the relationship grew out of Electro's original cost-cutting interests and what "appropriateness" of outsourced services means for Electro representatives. The data gaps required us to focus on particular stakeholders when analysing the contractor's attempts to build legitimacy, as elaborated upon below, rather than an attempt to assess whether legitimacy was actually gained in the client's eyes.

Background information about the contractual relationship and Pivot, in general, was gained at the initial meeting: employees and managers at Pivot presented their organisation and work, and the researchers could ask them questions. Also present at that meeting was an Electro representative. The interviews that followed were semi-structured - while the themes were defined at the outset, the structure and final content took shape in the course of every interview. Through this method, the interviewees had an opportunity to raise issues that were important from their perspective (Shank, 2002). The interview guide was designed 
to adjust the themes to the interviewee. Among the themes discussed with people from Pivot were the interviewee's background, day-to-day work and communication with the client, along with perceptions of his or her work in addition to the procedures, performance evaluations, and other controls in place. Among the themes discussed at Electro were how the company and its operations can be characterised with regard to the global and local environment, the respondents' educational background, the scope of the tasks that Pivot was handling, processes transferred to Pivot, relations and communication between Pivot and Electro and an assessment of the outsourcing of processes.

Analysis of the data followed abductive reasoning, with the empirical materials continuously informing the theoretical view and vice versa (Järvenpää, 2007). We started with open coding of interview transcripts and presentations (Neuman, 2007), with the aid of NVivo software. This coding enabled us to identify the most important themes discussed and also to perform second-stage coding for further analysis of these themes. The first-stage themes identified from the interviews were, among others, description of work duties, development of the processes, perceptions of one's work and skills needed in the work. Also, the various controls discussed were categorised by means of selective coding (Neuman, 2007). In the second stage, for example, the work descriptions were broken down further, into individual tasks, and the perceptions of one's work were grouped under advantages and challenges. This initial analysis revealed conflicts of interest connected with the fact that following the client's express wishes diminishes the role of the contractor and impoverishes the work of its employees. Moreover, we noticed how the interviewees and presenters referred to controls when they were attempting to illustrate the benefits and appropriateness of what they do. It was at this point that we identified the most important stakeholders whose interests had emerged in the data (the client, the contractor and the contractor's employees) as the focus of our research. While there were indications that, additionally, the Electro controllers to whom Pivot delivers the reports generated are important stakeholders with certain interests, the data indicated that addressing the interests of these employees is seen as the responsibility of their supervisors at Electro. With further data from Electro remaining unavailable, we were forced to focus our exploration on how Pivot intends to address the interests of the client (or more generally, the field of potential clients) at an (inter-) organisation level, and we were unable to embark on an indepth examination of the interests of individual boundary-spanners at Electro (as a specific client).

The picture emerging from the analysis was enhanced by an examination of the presentation slides and by the communication between Pivot and the research team. Even in this material, there seemed to be some symbolic aspects to the talk about efficiency, and these findings led us to consider taking the legitimacy perspective for fleshing out our view on how controls operate in addressing conflicting interests. Hence, the legitimacy perspective informed a further round of selective coding, for ascertaining which ways of demonstrating appropriateness for various stakeholders had been described, what types of legitimacy-building these represent and how the earlier analysis of controls might be integrated into the picture. At this stage, the final research question was formulated. While it was obvious from the data that the controls were often centred on the value obtained by the client, we gained a more nuanced understanding via a few additional interviews conducted in light of our preliminary conceptualisation of the potential symbolic aspects the controls may possess. In addition, we refined our understanding of the client's interests via a search for publicly available material, with collection of more data directly from Electro having proved infeasible (Kraus and Strömsten, 2016). These data and a rereading of the literature on controls in inter-organisational relationships with an eye on issues of 
QRAM 17,3

conflicting interests helped us gain a deeper understanding of our material. Moreover, dealing with our data properly in the final round of selective coding necessitated distinguishing and drawing together the concepts of value and legitimacy in a manner that demanded a closer look at the definitions of legitimacy and its dimensions. This work crystallised the conclusion that creating value and efficiency is not incompatible with orientation towards legitimacy. The process of abductive reasoning, ultimately, led to discerning the patterns described below.

\section{Addressing conflicting interests by building legitimacy via controls \\ 4.1 Conflicting interests and the contractor's need for legitimacy}

Because Electro as an organisation was interested mainly in cutting costs and increasing the quality of its management accounting reports (where "quality" is represented by standardised reports delivered on time without errors), there was a desire for automation whereby the client can automatically generate the required report by selecting the relevant market in a system interface and clicking a button. Many errors can be eliminated in this way, and the time expended on reporting is reduced. Such a development requires knowledge of various technological tools for reporting on Pivot's part:

[We see Pivot as helping] in changing [the work] from providing static reports or old classic Excel reporting to automated and dynamic dashboards, using [several kinds of technological tools]. (Chief Manager of Financial Management Systems, Electro)

While Pivot's help is needed for implementing technological tools, the only thing remaining for Pivot to handle after that deployment and automation is administration for the report templates and maintenance of the system, which takes only a few hours per financial quarter. In consequence, administration work no longer requires as much knowledge, and it can be handled in India, where labour costs are even lower than in CEE.

And that's why also already some simpler reports have gone from [Pivot offices] to India. There you have additional wage arbitrage. If it is pretty straightforward and pretty basic, people in India can easily take on this job. (Partnership Development Director of Finance Operations, Electro)

Also pointing to possible dangers down the road for Pivot, this extract summarises Electro's interest in Pivot's services for process development that enables standardisation and the use of technological tools therein, yielding sustainable reporting that is easy to manage. As the portfolio of services outsourced to Pivot had already become somewhat mature at the time of the research, transferring further transactions to Pivot was becoming rarer and rarer. While Pivot had proved to be a valuable partner to Electro, doing what Electro asked was narrowing the contractor's role constantly, as one manager at Pivot explained:

In practice, we are becoming an IT team, preparing templates, changing them, looking for data in various systems, maintaining systems [...]. It's no longer management accounting [...] With this automation and associated improvements, we're cutting the branch on which we sit.

There seems to be a general tendency in the outsourcing industry towards automating many transactional tasks currently performed by humans. That in itself reduces the role of a contractor to something closer to that of an IT service provider administrating information systems. This development, visible in the mature relationship between Pivot and Electro, has forced Pivot to consider its service portfolio carefully:

There are a lot of transactional tasks done by process assistants and process executives that in 10 years will be somewhat automated, robotised. [.. .] [T] he [contractor] needs to find an answer and 
concentrate more on these high-level services where the decision [and] analyses making use of the human brain are needed. (Manager at Pivot)

Such musings illustrate a keen awareness that meeting the annual cost-reduction targets of Electro does not serve Pivot's long-term interests. To remain in operation and provide more "high-end" services, Pivot has a general desire to not only provide technical services but also participate in the actual analysis of information and act as consultants instead of an IT team or, better yet, business partners making decisions based on the data they produce, as one manager there specified:

Yes, this is our long-term strategy: to become consultants [. . . . But do you know what we want, what our target is? Participating in the decision-making. We want to make decisions on the basis of our reports; smaller ones at first, [. . . ] then bigger ones.

This vision for the long term is set in stark contrast against Electro's interest in keeping its business analysis internal while Pivot merely provides the information and technical contributions that assist with decision making, as Pivot's management accounting director explained:

They [in Electro] don't want to give this to us, but our target still is to also be like a consultant and not just the one who is doing the 'service thing' [ . . . The person who is providing a service to the company wants to be perceived as a consultant too, providing the solutions too.

Because of the developments described above, extending the scope so as to safeguard Pivot's existing activities and also pursue the aspirations identified in the extract demands that Electro or other clients transfer to Pivot such special and advanced tasks that cannot be further relocated.

To fulfil both its own organisational aspirations and those of Electro, Pivot needs to rely on expert workers. The company's director of management accounting described the competencies this requires of Pivot employees:

We don't just need to develop our IT skills: programming, SQL, etc. We need financial analysts too. IT-system specialists will improve the tools, but interpretation and analysis will be carried out by analysts.

With the simplest tasks being accomplished elsewhere, retaining experts for what remains and maintaining their competence is extremely important, whether this involves technical skills or analytical talent. The issue is characteristic of outsourced management accounting services in particular as compared to many other services. For example, the management accounting director cited looking after the company's labour as one of his most important tasks:

We must verify regularly whether they are satisfied, whether everything is OK within the team. The most important thing is people - we don't have any other resources.

Retaining skilled personnel or attracting more may not always be easy, as those people have their own interests to consider. Although management accounting services are "high-end" on the broad spectrum of (accounting) services covered by the BPO organisation, and the employees likewise consider management accounting the most esteemed line of work at their delivery centre, the work delivering annual cost cuts and quality improvements suffers from downsides that echo those of shared services in general. The traits of the work left to the employees run counter to their interests. The same standardisation and elimination of errors that are essential for satisfying the client's interests render the tasks that remain for them rather simple and repetitive, and, notwithstanding the co-operation with the client, the
Controlling outsourced management 
QRAM 17,3

\section{8}

boundary-spanning work may remain shallow with regard to the information contained in the reports:

I would like to see also something different. Outsourcing is connected with some restrictions and simplifications. Those processes are repetitive. (Process Executive)

I'd like to work in the control department of a production company. Being closer to the core business is the most interesting thing. You see results, and you collaborate with different managers at the company - I mean operations managers. You're not a provider of services but a partner in the business. (Process Manager)

Especially at times of peak reporting volume, there is a large amount of stress, as turnaround times should be short while deliveries are often dependent on certain information from the client. At the same time, boundary-spanning involves handling a constant flow of changes aimed at compliance with the client's requirements. Various ad hoc tasks create their own stress, in that the remoteness from the operations reported upon makes understanding and filling the requests difficult.

For example, now I am working on just such a stressful ad hoc [task]. They need some report, and they don't have the faintest idea where those data are. I have to find out how to get the data for this report. I've been searching various systems and can't find [the data]. (Process Manager)

Such comments illustrate that satisfying the client's interests renders the boundaryspanning work at the contractor interface somewhat unappealing to a competent employee who could find employment elsewhere. Accordingly, Pivot's employees as individuals constitute another stakeholder for legitimatisation.

The picture painted above of where Pivot stands as a contractor in outsourced management accounting can be summed up thus: at an inter-organisational level and by serving the client's interests, Pivot is constantly narrowing the range of its duties and finding itself further from becoming a business partner or consultant. Responding in this way to the client's overt interests does not dovetail with the contractor's own long-term interest. Moreover, the employees are Pivot's most important resource, both for addressing the company's interest in having competent employees at hand who can perform more management-accounting-type analysis, and for serving the client's interest related to technical process developments directed towards cost-cutting and higher quality. The contradiction faced by the contractor is experienced at the level of individual employees, too: the worker's desire for meaningful work is juxtaposed with the organisational client's interest in standardised repeated processes and in the handling of complicated requests that lack any connection to actual business. Against this backdrop, it is necessary for Pivot to showcase its appropriateness to the client (and potential clients) as a provider of more and more specialised services while at the same time demonstrating that it is an appropriate workplace for skilled employees. In the following subsections, we explore the implications of controls in the relationship and building legitimacy cutting across these different interests.

\subsection{Controls and intended legitimacy in the relationship with the client(s)}

Controls play an important role in reaping the benefits of lower costs and higher quality, and thereby they have a part in demonstrating the episodic pragmatic legitimacy in the day-today exchange of utility. The inter-organisational service level agreement (SLA) lays the ground for the controls, which have been developed in collaboration to conform to the client's needs: 
[T] he contract[ual] obligations between [Electro] and [Pivot] - I mean the SLA, where you have information [on] what they should do, how, when, [about] time and quality [requirements] - those more generic things [...] are more 'given' by the SLA [...]. As our collaboration is mature, over the years we have participated in shaping those control mechanisms. (Chief Manager of Financial Management Systems, Electro)

The SLA defines performance requirements in numeric form at an inter-organisational level and upper management monitor the indicators. The requirements then roll down until reaching the level of the individual, where each boundary-spanner's performance is evaluated biannually. The formal procedure for performance evaluations encompasses both numeric measurements and self-assessment. In combination with performance evaluations, rule-based instructions manifest one aspect of utility exchange, specifying and co-ordinating the activities. For each report, work instructions of this nature go into great detail in how they address everything, from formatting to the generation of the reports. Pivot's employees are responsible for preparing the instructions when a given transaction is transferred to them, but Electro participates in the process and approves the final instructions.

While a "basic" set of controls can be found in the exchange and the influence described above, the intentions to build pragmatic legitimacy by demonstrations of conformance to requirements via controls go beyond these. The client is granted further influence in that its representatives evaluate each Pivot employee they work with. This evaluation follows a format similar to that of the employee's self-evaluation. It is noteworthy that such responsiveness to the client's general needs is displayed even though not all representatives higher up in Electro find true utility in this evaluation relative to the key performance indicators (KPIs):

But I want to have KPIs useful for my engagement that I have with [Pivot]. Personally [...], I don't see usefulness of this assessment of [Pivot] employees by us. (Chief Manager of Financial Management Systems, Electro)

The controls have also been developed to articulate the ideals for behaviour in Pivot. The SLA-rooted performance targets that roll down through the organisation represent neither the client's nor Pivot's episodic inspections of efficiency; rather, they constitute general representations of the utility Pivot creates. Namely, the numbers form a key element of the talk, and thus a way for strategic communication about the improvement in the tasks outsourced. Specific examples of accomplishments are presented as general illustrations to create perceptions of appropriateness. For example, a process manager described the developments to a reporting process that had once involved more than 20 local controllers each devoting two days per quarter to creating certain reports. When initially transferred to Pivot, the process took about $80 \mathrm{~h}$ a quarter. This was reduced in stages to $36 \mathrm{~h}$ and ultimately, after automation, to four hours each quarter, designated as for maintenance. In this way, the performance indicators start to represent dispositions, the values held in common between client and contractor. The phenomenon is visible at all levels of Pivot as employees present efficiency as an essential characteristic of their work, not just utility created for the client:

This [is] value added for all of us: they have better and faster reports; we don't spend so much time creating those reports. (Process Manager)

We try to automate the work, even when they do not request us to do so. We want to make those reports easy for us to prepare too, for our own convenience. (Management Accounting Specialist) 
QRAM 17,3

Such talk pertains not just to reports that can be standardised. Numbers, such as how many prices get calculated incorrectly or the volume of questions submitted by the client, also symbolise the quality of more specialised processes, such as the above-mentioned transfer pricing:

When we started, the number of prices that were incorrectly calculated was, as you can see, 11, almost 12 per cent. Now [...] we are below five per cent for incorrectly calculated prices [....]. In the beginning, there were a lot of e-mails received, whatever queries, questions, wrong prices, missing prices. Now [...], [w]e've improved and receive many fewer queries. (Process Manager)

Individual employees are important in the legitimisation, with the boundary-spanning element of the work being visible in the communication channels, which are documented so as to formalise the influence processes within the organisational structure. Each employee of Pivot is responsible for the inter-organisational relationship within the limits of his or her responsibilities and has specifically designated contact with Electro representatives. Communication is regular and recurrent:

Each week, we discuss details with [Electro], how we do things, how we do the processing [...]. (Director)

While such contacts might exist as formal definitions demonstrating possibilities for influence rather than real-world actions, there is more to them than that. The intensity of these relations is reflected in the fact that the contacts may even develop into personal relationships:

You know that, thanks to these communications, we have couples [between Pivot and Electro] who have got married too [.... . That's the result of this communication! (Management Accounting Specialist)

To build a more stable basis for its operations, pragmatic legitimacy is not enough but Pivot also intends to build cognitive legitimacy, with a view to becoming an integral and permanent part of Electro's management accounting. Indeed, the controls seem to foster interconnections with the client that may support permanence. In some cases, Pivot is the sole possessor of valuable information, on account of how transactions have been arranged between the two firms. For example, administration of transfer pricing is organised in such a way that Pivot holds all the information and knowledge related to Electro's transfer pricing and is responsible for the full body of data and all the associated processes. As this work lends itself less well to standardisation than the generation of regular reports does, each of the problems that arise in transfer pricing is unique:

Some requests are easy: 'I do not have [a] price in the system: calculate it because the truck [is waiting] to be loaded' [...]. There are also some more complicated requests: 'The price in the system is $€ X$. It should be $€$ Y. Check it.' [...] I don't remember any of my tasks ever being repeated. (Senior Business Analyst)

Moreover, the work instructions hold value in providing information that may be important with regard to even the most standard of reports. They contain a description of the background for the report, which may offer exactly what is needed for realising smooth cooperation with the client:

A funny thing [happened] recently. An entity asked me why I prepare [a particular] report, because they forgot why they needed it! Then from the instructions, I found where in the process they need this report. (Management Accounting Specialist) 
Furthermore, Pivot has come to excel at the development of lean thinking, which was initially an adaptation to the client's ways of working. It entails procedures that aid in demonstrating the improvements to the process when the time comes to map and assess the amounts of time required for certain tasks. While mapping such details provides an opportunity to demonstrate utility exchange and conformance to established models, Pivot has gone further than that. They have even exceeded the client's requirements, throughout the process, and Pivot now advises Electro on lean thinking. For Pivot, this is a valuable demonstration of consulting ability, beyond provision of information and assistance with technical matters:

We implemented a Lean programme because [Electro] had implemented one, but now we are more advanced than they are, so they are learning from us and trying to copy some elements that are working perfectly in [Pivot]. (Director)

Such pieces of information and knowledge may lead to individual boundary-spanners' work and Pivot's activities, in general, being indispensable to Electro, thereby fostering interconnection, integrating Pivot into the client's operations, and thus complicating further efforts to move tasks to India. Responding sufficiently to the client's interests can also be portrayed as dictating still more extensive handling of specialised transactions. This expansion of scope, whereby Pivot intends to safeguard its existing operations and ensure work for its employees, boils down to expressing the predictability and plausibility of transactions, traits identified by, for example, a junior controller at Electro who was working with people from several units of Pivot's business group.

The interaction with [Pivot employees] is very good [...]. Most of the people [...] are able to support us and help to resolve any issues. [...] [In contrast,] we see many mistakes in booking invoices by people from India. What's more, if any problem appears, they don't try to solve it themselves but usually contact us and ask what they should do. It seems that operations employees in India do not have sufficient support from their managers. (Junior Controller, Electro)

Not only are the individual processes or transactions formalised as instructions but also the general management of each process has its own procedures. Pivot has even created models that visually showcase the guaranteed quality and reliability of its services, thereby supporting its employees' efforts to accomplish whatever is required. The knowledgemanagement procedure exemplifies this. This is a model for work routines that is intended to make any process or transaction independent of any specific person. The procedure formalises the manner in which procedures, instructions and designations of backup personnel for every position are created. It thereby encapsulates the very essence of demonstrating the infallibility of even a specialised service, as described by a Pivot team manager:

So, first of all, we have the first maturity level, where we have work instructions for each of the processes. We have access and authorisations [...]. And we have, of course, the backup group $[\ldots]$. The second maturity level [...] means we are measuring whether the backups can perform the activities [...]. And we have backup and hand-over auditors, special auditors to perform once a month - an audit [of whether] the person can really perform all the tasks [...]. The third maturity level is the procedure for customer information about personnel changes [...], whom they should contact. And [...] after five or six months, we send [a survey for verification purposes] to the customer.

Pivot was also planning to patent the process-advancement model. This represents a process that proceeds in stages from the standardisation and stabilisation of simple tasks and processes, continues with an implementation of improvements, and in its last stage 
QRAM 17,3

concentrates on the more advanced tasks of pursuing innovation and consultancy value embodying Pivot's long-term aspirations. The management accounting director explained how the process-advancement model depicts continuous improvement as a professional endeavour while acknowledging that the processes' most advanced development remains confined to the realm of aspirations:

[The process-advancement model] is a programme aimed at making us work as consultants, suggesting [to the] client new technologies and new services [...]. The 'first level' means do what you do; the 'second level' means do what you do but improve, do it better; and the 'third level' denotes 'be innovative, invent what could be transferred from [the] client, change the process, use new tools [e.g. new IT applications instead of Excel]'. [The fourth] part will be 'become a consultant, adding value [for the] client'. For a new client, you are starting at [the] first level; with Electro, we are now at [the] third level.

The work models show that the controls are no longer something employed purely because of the requirements of the current main client, if they ever were. They have become mechanisms by which Pivot can validate and ensure its professionalism in delivering the services:

We show them [Electro] that we check and control, and that we have various control tools. But, frankly speaking, they are not very interested. However, we feel that it makes our collaboration deeper, safer, and credible. You know, all those mechanisms were implemented some time ago, so they know that all of the controls work perfectly, that we take care of them. (Director)

The communication of the professionalism is not confined to the current client. Pivot also uses the work models to communicate that specialised services such as management accounting are amenable to outsourcing in their intentions to demonstrate the comprehensibility of such new services to potential clients. Thus, the controls developed with one client represent the more general intentions of legitimation in the field of potential clients.

\subsection{Controls and legitimacy among employees}

As described in Section 4.1, while Pivot would prefer competent employees with skills in analysis, the boundary-spanning work accomplished for Electro encompasses numerous elements that render the work unappealing to professionals. Even the controls put in place to fulfil the client's requirements, such as lean thinking, may not only annoy experts but also take time away from core tasks:

We write down [all the tasks we accomplished that day] in [. . . this [Lean] table, and we also specify the time used for every ad hoc task [. . . ]. Sometimes [I spend] more [time on self-reporting] than preparing regular reports for the clients. But those are the corporate rules, and we have to abide by them. (Process Executive)

Therefore, something must be done to conform to the interests of current and potential employees. Moreover, the conformance must be communicated, for example, by showing the benefits of working for a provider of outsourced management accounting services. Indeed, Pivot has exhibited a willingness to devote attention to the benefits for its employees. These were characterised thus:

We try to make our employees satisfied with the work. We offer them various kinds of training to develop their skills, to make them confident that they won't [find their skills deteriorating at Pivot]. (HR Manager) 
Moreover, the job descriptions have been designed so as to refer not only to handling Electro's transactions and self-reporting but also to personal-level development opportunities. Accordingly, the job has two sides: development opportunities, in parallel with the simple, perhaps boring work for the client. This has borne fruit in the employees recognising the positive facets:

The work is great for me! I learn all the time. I feel that I'm developing my skills. (Management Accounting Specialist)

I have many opportunities and possibilities for self-development. (Process Manager)

To demonstrate its appropriateness as a workplace, Pivot's controls conform to demonstrate pragmatic legitimacy, specifically utility exchange, with the company offering internal training at various stages on the career path, focussed on technical and interpersonal skills. Also, the company offers employees opportunities to educate themselves in other ways - for instance, by financing courses provided by external organisations such as ACCA or CIMA:

Oh, yes, there is generally a very strong impact on skill-development here: if you only want this or wish for that, you can spread your wings [...]; you don't have to fight to get training [...]. They push you to train yourself. (Business Analyst)

This is handled mainly in connection with performance evaluations. Alongside the performance measurements that roll down from the SLA, there are interactional performance evaluations for individual employees. Through these, the employees themselves can influence the process, which encompasses both an evaluation discussion with the team manager and self-evaluation, centred on personal development. For promotion purposes, training, knowledge and active participation in continuous development are factors considered alongside the "hard numbers" in the performance evaluation. An employee judged to be excellent twice in a row with regard to these elements will most probably be promoted, In fact, the team managers' job focusses mainly on helping the team members develop in the process.

Promotions and alternative positions are readily available, as the scale of the company means that numerous opportunities for promotion exist beyond the sphere of the delivery centre's management accounting services:

[The company] offers many opportunities and avenues for development. You can develop as a manager, as a project manager, or as a technical expert. [The other interviewee present] likes meeting clients, offering them new solutions, implementing the solutions, improving them. I prefer managing people, being a personal leader. And you can choose what you prefer [....]. Now I plan to change position [...] I will be the team manager of the consolidation team, so it is a promotion [...]. In my evaluation discussions with my team manager, I always insisted on managing people. Now I've finally had the proposal [accepted], so I must take it. (Process Specialist)

While the practices described above demonstrate utility exchange, influence and adaptation to the employees' desires for self-development, they are more than building pragmatic legitimacy. These procedures ensure that the possibilities for development are not a matter of chance: a clear link is drawn between positive consequences and the individual-level performance evaluation reflecting moral legitimacy. Structured procedures for evaluation of performance demonstrably create fair consequences that conform to employees' ideals of a good workplace and communicating them to create an image of a workplace offering them development opportunities and thus demonstrating the general rightness of the contractor's actions towards its employees. The company encourages workers to remain at Pivot by 
QRAM 17,3

ensuring that they can develop their skills and competencies there (e.g. through working in other positions), and the well-structured opportunities seem to have paid off in making Pivot a more attractive place to work.

[I] plan to continue my career path in [this company]. There are so many opportunities here, to change department, position within [the company]. (Process Manager)

I would like to stay in this company but maybe as a process manager. I do not want to become Team Manager. I am not interested in managing people. I prefer operations work. (Management Accounting Specialist)

These extracts indicate that, in general, the employees assessed Pivot to be a good place to work, regardless of the unpleasant characteristics of outsourced accounting work, with appreciation being expressed for the possibility to develop one's skills for the future and trying different kinds of job. This does not occur automatically. Not all departments of the $\mathrm{BPO}$ organisation were up to Pivot's standards in terms of structured procedures and work descriptions for both arranging the work and enabling this. Pivot's attention to this was selfevident, in contrast, as one informant noted:

In my previous work [at this BPO firm], I had tough periods and then nothing to do. Here everything is perfectly organised! (Process Executive)

Accordingly, the controls would seem to have succeeded in creating a positive image related to Pivot's benefits and general appropriateness as an employer organisation among individual employees, with many interviewees actually stating that friends or acquaintances already working for Pivot had recommended applying for a job there. This neatly illustrates that Pivot employees see this as a desirable workplace and disseminate their view, which may also build legitimacy more generally in the field of potential employees. Altering perceptions by communicating the image of the workplace thus also happens unofficially.

\section{Discussion}

As the preceding descriptions indicate, controls within the inter-organisational relationship are tightly intertwined. At an inter-organisational level, the SLA is the most important control, but it rolls down to more intra-organisational controls that steer individual boundary-spanners' work towards the client's interests. These controls mainly intended to build legitimacy with the client, work in demonstrating appropriateness in multiple ways and also have various effects on the relationship. Pragmatic legitimacy, entailing the display of the benefits created that conform to the needs of the client has been the most important way to build legitimacy with the case client, to nurture co-ordination in the relationship at organisation level. The controls' utility-demonstrating properties are specifically intended to articulate conformance to the rationale identified as the norm in centralising/outsourcing activities generally (Hyvönen et al., 2012), in line with studies focused on preventing opportunistic behaviour from a cost perspective (Dekker, 2004; Langfield-Smith and Smith, 2003; Nicholson et al., 2006; Van der Meer-Kooistra and Vosselman, 2000). However, the intentions to demonstrate influence and shared disposition may benefit from controls too, and extend building pragmatic legitimacy beyond utility exchange connected with episodic demonstrations of cost-cutting and quality. In fact, focussing solely on client-side utility has negative effects on both the contractor and its individual employees, thus undermining their long-term interests. These conflicting interests are especially prevalent in the setting of outsourced management accounting services, which typically are firm-specific (whereas many elements of bookkeeping or payroll accounting are not). With the contractor having an 
interest in preserving and developing its 'high-end' status while also delivering process improvements and automation, a conflict of interest emerges at an organisational identity level (Thrane and Hald, 2006) because the client wants mere technical assistance whereas the contractor desires to be considered a consultant and analyst. Accordingly, the contractor also intends to build cognitive legitimacy with the help of controls, as permanence with the client may be ensured by fostering an interconnection that renders the contractor indispensable. In addition, controls serve the contractor's long-term interest by demonstrating not only utility but also predictability and plausibility with the outsourcing of more and more specialised services, thus increasing its legitimacy as a provider of specialist management accounting services. Among the mechanisms involved are modelling processes that enable the communicating of the contractor's work as comprehensible even in the field of potential clients.

This conflict of interests further underscores that neither interest mentioned above can be served without the important resource and stakeholder represented by the contractor's employees, in that the work of these boundary-spanners also legitimates the contractor's presence for the client. Hence, the fact that some boundary-spanners in such interorganisational relationships are not managers applying controls, but lower-level employees also subject to them (Zahir-ul-Hassan et al., 2016) does not render these individuals less important to the relationship. Outsourced management accounting entails mastering technological tools at the very minimum, so employees' knowledge and know-how are important in this regard, whether related to skills in analysis (desired by the contractor) or skills with technological tools for providing information (desired by the client). While retaining the 'high-end' status of management accounting, the work shares many of the negative attributes of shared services in general, principal among them, repetitive, simple work that occasionally is very stressful, often on account of its boundary-spanning nature and controls focused on client-side cost-efficiency (Dekker, 2016). These factors and the controls ensuring them specifically render employees susceptible to knowledgenarrowing that is detrimental to their career (Nicholson and Aman, 2012; Seal and Herbert, 2013). The legitimacy perspective thus redefines another possible relationship within interand intra-organisational controls (Coad and Cullen, 2006; Håkansson and Lind, 2004; Mouritsen et al., 2001; Seal et al., 2004; Thrane and Hald, 2006). Namely, controls of an interorganisational nature render some more intra-organisational controls necessary as they limit the freedom to act within the contractor organisation. For example, demonstrating appropriateness to employees, to build legitimacy between the organisation and individuals, is not a matter of exchange and influence attributes of pragmatic legitimacy alone; it may be interpreted also as responding to general ideals and, in turn, creating a positive overall evaluation of the workplace, thus building moral legitimacy. All of these elements conforming to self-interest and ideals need to be attested in the performance-evaluation processes, wherein inter-organisational, organisational and individual-level interests are actually intertwined, as are the controls serving those interests (Carlsson-Wall et al., 2016; Schäffer et al., 2015). Conflict manifests itself when the contractor intends to satisfy the client's utility interests (build pragmatic legitimacy) at an inter-organisational level: ensuring technical efficiency for the client vs. the employees' interest in developing their knowledge and competence. Ultimately, the client's interests too are served by the contractor being able to retain its competent employees, and the contractor's and employees' interests are even better aligned with both parties aiming at meaningful, "high-end" work. Table 2 summarises the empirical results, depicting how the different yet interwoven controls tie in with the multiple dimensions and strategies of building legitimacy. 
QRAM

17,3

\section{6}

Table 2.

Summary of empirical findings
Legitimacy building strategies

The main controls used

Pragmatic legitimacy: utility delivered to the client by the contractor Exchange attributes

Adapting and conforming to the stakeholders' needs by evaluating and monitoring adaptation. Communicating the conformance Specifying and co-ordinating activities by automation and standardisation

Influence attributes Co-opting client into daily activities

Dispositional attributes

Adapting and communicating conformity to stakeholders' values by using certain language

SLA, Performance metrics from company to individual level, lean thinking

Procedures, work instructions, lean thinking

Defined communication channels employee assessment by the client Using efficiency figures as symbols in the daily language

Utility delivered to the contactor's current (and potential employees Conforming to employees needs for development, standardising employee development procedures and co-opting employees into these procedures Communicating the conformance

Development discussions including individual performance evaluations

\section{Benefits}

Moral legitimacy: a general positive normative evaluation ('rightness of actions') of the contractor and its activities by the current (and potential) employees

Consequences

Conforming to ideals of fair consequences of actions, such as

Support and benefits meaningfulness of work and possibilities for personal development

Procedures Demonstrating the above in procedures

Opportunities for training and education

Development discussions including individual performance evaluation structuring the possibilities for training and education

Cognitive legitimacy: Comprehensibility of the contractor and its operations and its "taken-for-grantedness" for client(s)

Predictability/ plausibility

Formalising and professionalising outsourced management accounting with the application of invented management models, presenting them as simple activities

Seeking patent for the invented models Fostering interconnections with the client by possessing valuable knowledge and information

Knowledge management procedure

Permanence

Process advancement model

Organisational structures, Procedures

Against the backdrop of our analysis, we can state that a legitimacy perspective explains more fully how controls expressed in routines may blur apparent conflicts of interest; they can address several types of appropriateness simultaneously, and thus address interests of multiple stakeholders (Coad and Cullen, 2006). The results illustrate that while the controls can be designed to conform to self-interest, ideals and social structures in the environment, legitimacy- 
building calls for this conformance to be demonstrated to manipulate the interpretations present in this environment (O'Dwyer et al., 2011; Suchman, 1995). Furthermore, empirical results identifying connections between a given control and the several ways of building legitimacy demonstrate the overlap between the dimensions of legitimacy, which are considered separate only for purposes of analysis (Deephouse and Suchman, 2008). For example, the influences on legitimacy among employees attest that it may be difficult to disentangle a control demonstrating benefits for the employees (pragmatic legitimacy) from showing fair consequences of good work (moral legitimacy) as defined by Suchman (1995). Pragmatic and moral legitimacies are thus connected even at their conceptual base. Suchman's view of building legitimacy in relation to the general rightness of the actions through fair consequences and procedures hence appears to entail a rather narrow and problematic definition even for analytic purposes, at least in the context of the present paper, where the contractor builds legitimacy among its employees. This is because utility in the form of career development may also be interpreted as a general right of employees.

Accordingly, acknowledging these multiple types of appropriateness illustrates that the possible effects of controls on perceptions and, through them, on legitimacy do not end with technical assurance and demonstrations of efficiency and benefits - the latter form only one way to demonstrate appropriateness, and a rather temporary one at that (Meyer and Rowan, 1977; Suchman, 1995). More enduring forms of legitimacy can be built with the aid of controls within the inter-organisational relationship, as controls incorporating symbolic displays are not isolated from those that really matter for dayto-day work (Schäffer et al., 2015; Siti-Nabiha and Scapens, 2005). This is not limited to performance metrics; one finds it also with communication channels, in that the economic concerns and socially approved ways of acting are fairly compatible and not fundamentally in conflict. Accordingly, the same controls enable the contractor to integrate its own aspirations with those of the client, as they can incorporate several interests - a finding in contrast with many pieces of accounting research illustrating decoupling in seeking legitimacy (Schäffer et al., 2015; Siti-Nabiha and Scapens, 2005). Moreover, fostering interconnections by possessing and using invaluable knowledge explains how the asset-specificity of transactions increases over time, such that the parties become "locked in", in line with the transaction cost-based view (Speklé, 2001; Vosselman, 2002). As the contractor is the only one holding the information or knowledge, its position may grow more permanent, perhaps even becoming taken for granted. This may be linked to the "high-end"-type services provided. Therefore, controls aimed at ensuring cost-efficiency and quality as expressly desired by the client do not merely define the relationship, the organisations' boundaries, and hence the conflicting interests (Mouritsen et al., 2001; Thrane and Hald, 2006). The same controls also provide opportunities for expanding the boundaries, by demonstrating appropriateness beyond utility exchange, as a legitimacy perspective elucidates. Moreover, they influence other stakeholders, such as boundary-spanners, creating an additional need for legitimacy-building among them. This is occurs because the controls not only co-ordinate by providing instructions for day-to-day routines and thus demonstrate utility exchange but also model the larger development processes that are part of the daily work of each and every employee of the contractor more generally. Hence, the controls aid in creating a perception that the execution of transactional processes is developed professionally, thereby building comprehensibility of the services even among a more general audience of potential clients (O'Dwyer et al., 2011; Suchman, 1995). 
QRAM

17,3

\section{Conclusions}

This paper's insights are centred on a contractor's perspective on controls in an interorganisational relationship for outsourced management accounting services wherein all contractor employees have a role as boundary-spanners and thereby some responsibility for managing the relationship (Dekker, 2016). Data were collected via presentations and interviews at various levels in the contractor organisation, with further validity for the work being achieved by complementing the data set with perspectives from the client's side. The conflicting interests inherent to such relationships were analysed with an emphasis on how controls are implemented with the intention of helping to meet the contractor's need to build legitimacy that arises from those conflicting interests. The legitimacy perspective was applied for its ability to draw attention to the multiplicity of interests and definitions of appropriateness. This enabled a detailed examination of how the symbolic properties of controls intended to build legitimacy with the client and facilitated an exploration of how those controls affect the boundary-spanners at lower levels in the inter-organisational relationship's hierarchy thereby creating a need to address legitimacy among them. This lens can both provide a snapshot view of how controls serve multiple interests in the interorganisational relationship by conforming to the social requirements and at the same time acknowledge how the relationship changes as the outsourced processes develop due to the controls.

The first contribution that this perspective makes to the literature on inter-organisational controls is in presenting the symbolic aspects of controls, which illustrate legitimacy within inter-organisational relationships rather than merely demonstrating technical properties intended to serve the client's overt interests or defining the conflicting interests (Mouritsen et al., 2001; Nicholson et al., 2006; Seal et al., 2004). More specifically, the results of the study crystallise the fact that the controls responding to the focal client's interest and steering the boundary-spanners' work at an inter-organisational level towards that interest do have effects within the relationship while at the same time also addressing several interests. It becomes evident in this context that efficiency is a necessary component of legitimacy, but not sufficient on its own to ensure the contractor's long-term operations. While legitimacy is often explored at an organisational level from the perspective of an important stakeholder, acknowledging multiple stakeholders and different ways to build legitimacy underscores that multiple norms of appropriateness co-exist, at several levels. As neither pure efficiency nor non-efficiency-linked legitimacy is enough in its own right for continuity of operations, management of perceptions by communication of conformance to several social norms is vital, for demonstration of efficiency needs to be complemented with more enduring forms of legitimacy (O'Dwyer et al., 2011). The case of a contractor supplying specialised services demonstrates a truth somewhat forgotten in institution-oriented accounting literature using the concept of legitimacy (Schäffer et al., 2015; Siti-Nabiha and Scapens, 2005) economic interests and legitimacy-building are not in conflict by definition, and the same controls may serve both in certain circumstances; after all, economic interests are also socially constructed (Meyer and Rowan, 1977).

While securing efficiency for the dominant partner is at the core of transaction cost-based literature (Nicholson et al., 2006; Dekker, 2004; Langfield-Smith and Smith, 2003; Van der MeerKooistra and Vosselman, 2000), the second contribution of this paper is associated with widening this perspective to a more in-depth examination of the role of employees steered by controls with regard to the boundary-spanning nature of their work (Coad and Cullen, 2006; Dekker, 2016; Van der Meer-Kooistra and Vosselman, 2000). Demonstrating utility exchange at an organisational level for the client via controls such as performance metrics and work instructions has negative consequences on employees, and thus actually necessitates 
legitimacy among individual boundary-spanning employees. Such legitimacy can be built with the aid of controls structured in human-resource practices interwoven with individual performance evaluations. Though the employee perspective has been mentioned both in literature on outsourcing of accounting (Nicholson and Aman, 2012; Seal and Herbert, 2013) and in that on inter-organisational controls (Coad and Cullen, 2006; Van der Meer-Kooistra and Vosselman, 2000), our analysis offers a more refined understanding. It explains how the boundary-spanners are affected by controls and how their interests at individual level can be served by controls designed mainly to satisfy the organisational client and bring it value (Dekker, 2016). The results thus highlight the important role of those boundary-spanners who are both influenced by controls and affect legitimacy at an inter-organisational level, while directly granting organisation legitimacy at an individual level.

By acknowledging the symbolic properties, the legitimacy perspective explains the paradox that the conflicting interests created by formalisation and standardisation of day-to-day work at odds with the contractor's long-term organisational interest can be addressed by means of formalisation and standardisation that is dis-embedded from that work, as work models create comprehensibility of the specialised services. While the study reported upon here started by exploring the multiplicity of interests within an inter-organisational relationship and how those interests are addressed via controls (Human and Provan, 2000; Moll and Hoque, 2011), there are indications that the internal interests create a need to build external legitimacy, too, such that controls within the relationship may spill-over beyond it. This is because the controls enable the contractor to fulfil its own long-term interest. While being deliberately employed to serve the client's interests, with an entire control system designed around them, the controls may also exert effects (intentional or not) that indicate a passive adaptation to general interests, effects that also go beyond the relevant relationship (Suchman, 1995). One example is employees possibly pointing work-seeking acquaintances towards their employer on account of finding their workplace satisfactory (appropriate). In another example of spill-over, the contractor can further apply models developed in the work performed with the current client: addressing wider audiences, even patenting models and transferring them to other settings and clients.

As with any research, the limitations of the study need to be acknowledged. The case presented puts the spotlight on the nascent stage of management accounting's outsourcing, with its potential for development and rapid evolution. This may not afford the painting of a complete picture of possible control arrangements, but allows a more general understanding of their role in building legitimacy, so opening avenues for future research. Additional opportunities for further research can be found in relation to addressing legitimacy concerns via controls in other kinds of inter-organisational relationships, including those with external legitimating stakeholders. It is worth noting in addition that, as was the work of Nicholson et al. (2006) and Kraus and Strömsten (2016), our research was limited by a paucity of interviews from the client's side. This restricted our ability to explore whether legitimacy with the client was actually gained and how legitimacy may be built with the client at the level of individual employees/controllers. That said, focussing on the contractor's perspective and one specific contractor-client relationship involving outsourced specialised services has enabled us to flesh out the picture of the controls within the relationship and also of the conflicting interests they must serve. Future research could contribute to a more nuanced understanding by showing whether a given way to build legitimacy is more important to some stakeholders than others. 


\section{QRAM}

17,3

\section{References}

Carlsson-Wall, M., Kraus, K. and Lind, J. (2011), "The interdependencies of intra-and interorganisational controls and work practices - the case of domestic care of the elderly", Management Accounting Research, Vol. 22 No. 4, pp. 313-329.

Carlsson-Wall, M., Kraus, K. and Messner, M. (2016), "Performance measurement systems and the enactment of different institutional logics: insights from a football organization", Management Accounting Research, Vol. 32, pp. 45-61.

Coad, A.F. and Cullen, J. (2006), "Inter-organisational cost management: towards an evolutionary perspective", Management Accounting Research, Vol. 17 No. 4, pp. 342-369.

Cuganesan, S. (2006), "The role of functional specialists in shaping controls within supply networks", Accounting, Auditing and Accountability Journal, Vol. 19 No. 4, pp. 465-492.

Dacin, M.T., Oliver, C. and Roy, J. (2007), "The legitimacy of strategic alliances: an institutional perspective", Strategic Management Journal, Vol. 28 No. 2, pp. 169-187.

Deegan, C. (2006), "Legitimacy theory", in Hoque, Z. (Ed.), Methodological Issues in Accounting Research: Theories and Methods, Spiramus Press, London, pp. 161-182.

Deephouse, D.L., Suchman, M., (2008), "Legitimacy in organizational institutionalism”, in Greenwood, R., Oliver, C., Sahlin, K. and Suddaby, R. (Eds), The SAGE Handbook of Organizational Institutionalism, SAGE, London, pp. 49-77.

Dekker, H.C. (2004), "Control of inter-organizational relationships: evidence on appropriation concerns and coordination requirements', accounting", Organizations and Society, Vol. 29 No. 1, pp. 27-49.

Dekker, H.C. (2016), "On the boundaries between intrafirm and interfirm management accounting research”, Management Accounting Research, Vol. 31, pp. 86-99.

Dent, J.F. (1991), "Accounting and organizational cultures: a field study of the emergence of a new organizational reality", Accounting, Organizations and Society, Vol. 16 No. 8, pp. 705-732.

Håkansson, H. and Lind, J. (2004), "Accounting and network coordination', accounting”, Organizations and Society, Vol. 29 No. 1, pp. 51-72.

Human, S.E. and Provan, K.G. (2000), "Legitimacy building in the evolution of small-firm multilateral networks: a comparative study of success and demise", Administrative Science Quarterly, Vol. 45 No. 2, pp. 327-365.

Hyvönen, T., Järvinen, J., Oulasvirta, L. and Pellinen, J. (2012), “Contracting out municipal accounting: the role of institutional entrepreneurship", Accounting, Auditing and Accountability Journal, Vol. 25 No. 6, pp. 944-963.

Järvenpää, M. (2007), "Making business partners: a case study on how management accounting culture was changed", European Accounting Review, Vol. 16 No. 1, pp. 99-142.

Kraus, K. and Lind, J. (2007), "Management control in inter-organisational relationships", in Hopper, T., Northcott, D. and Scapens, R. (Eds), Issues in Management Accounting, Pearson, Harlow, pp. 269-296.

Kraus, K. and Strömsten, T. (2016), "Internal/inter-firm control dynamics and power - a case study of the Ericsson-Vodafone relationship", Management Accounting Research, Vol. 33, pp. 61-72.

Kumar, R. and Andersen, P.H. (2000), "Inter firm diversity and the management of meaning in international strategic alliances”, International Business Review, Vol. 9 No. 2, pp. 237-252.

Kumar, R. and Das, T.K. (2007), "Interpartner legitimacy in the alliance development process", Journal of Management Studies, pp. 1425-1453.

Langfield-Smith, K. and Smith, D. (2003), "Management control systems and trust in outsourcing relationships", Management Accounting Research, Vol. 14 No. 3, pp. 281-307.

McIvor, R., McCracken, M. and McHugh, M. (2011), "Creating outsourced shared services arrangements: lessons from the public sector", European Management Journal, Vol. 29 No. 6, pp. 448-461. 
Malmi, T. and Brown, D.A. (2008), "Management control systems as a package - opportunities, challenges and research directions", Management Accounting Research, Vol. 19 No. 4, pp. 287-300.

Meira, J., Kartalis, N.D., Tsamenyi, M. and Cullen, J. (2010), "Management controls and inter-firm relationships: a review", Journal of Accounting and Organizational Change, Vol. 6 No. 1, pp. 149-169.

Merchant, K.A. and Van der Stede, W.A. (2012), "Management control systems: performance measurement", Evaluation and Incentives, FT Prentice Hall, Harlow.

Meyer, J.W. and Rowan, B. (1977), "Institutionalized organizations: formal structure as myth and ceremony', The", American Journal of Sociology, Vol. 83 No. 2, pp. 340-363.

Moll, J. and Hoque, Z. (2011), "Budgeting for legitimacy: the case of an Australian university', accounting", Organizations and Society, Vol. 36 No. 2, pp. 86-101.

Mouritsen, J., Hansen, A. and Hansen, C.Ø. (2001), "Inter-organizational controls and organizational competencies: episodes around target cost management/functional analysis and open book accounting", Management Accounting Research, Vol. 12 No. 2, pp. 221-244.

Mouritsen, J. and Thrane, S. (2006), "Accounting, network complementarities and the development of inter-organisational relations', accounting”, Organizations and Society, Vol. 31 No. 3, pp. 241-275.

Neuman, W.L. (2007), Basics of Social Research: Qualitative and Quantitative Approaches, Pearson/ Allyn and Bacon, Boston, MA.

Nicholson, B. and Aman, A. (2012), "Managing attrition in offshore finance and accounting outsourcing: exploring the interplay of competing institutional logics', strategic outsourcing”, Strategic Outsourcing: An International Journal, Vol. 5 No. 3, pp. 232-247.

Nicholson, B., Jones, J. and Espenlaub, S. (2006), “Transaction costs and control of outsourced accounting: case evidence from India”, Management Accounting Research, Vol. 17 No. 3, pp. 238-258.

O'Dwyer, B., Owen, D. and Unerman, J. (2011), "Seeking legitimacy for new assurance forms: the case of assurance on sustainability reporting", Accounting, Organizations and Society, Vol. 36 No. 1, pp. 31-52.

Oliver, C. (1991), "Strategic responses to institutional processes", The Academy of Management Review, Vol. 16 No. 1, pp. 145-179.

Scapens, R.W. (1990), "Researching management accounting practice: the role of case study methods", The British Accounting Review, Vol. 22 No. 3, pp. 259-281.

Scapens, R.W. and Macintosh, N.B. (1996), "Structure and agency in management accounting research: a response to boland's interpretive act, accounting", Organizations and Society, Vol. 21 Nos 7/8, pp. 675-690.

Scapens, R.W. and Varoutsa, E. (2010), "Accounting in inter-organisational relationships - the institutional theory perspective", in Håkansson, H., Kraus, K. and Lind, J. (Eds), Accounting in Networks, Routledge, New York, NY, pp. 314-341.

Schäffer, U., Strauss, E. and Zecher, C. (2015), "The role of management control systems in situations of institutional complexity", Qualitative Research in Accounting and Management, Vol. 12 No. 4, pp. 395-424.

Seal, W., Berry, A. and Cullen, J. (2004), "Disembedding the supply chain: institutionalized reflexivity and inter-firm accounting', accounting”, Organizations and Society, Vol. 29 No. 1, pp. 73-92.

Seal, W. and Herbert, I. (2013), "Shared service centres and the role of the finance function: advancing the iron cage?", Journal of Accounting and Organizational Change, Vol. 9 No. 2, pp. 188-205.

Shank, G.D. (2002), Qualitative Research: A Personal Skills Approach, Prentice-Hall, Upper Saddle River, $\mathrm{NJ}$.

Siti-Nabiha, A.K. and Scapens, R.W. (2005), "Stability and change: an institutionalist study of management accounting change", Accounting, Auditing and Accountability Journal, Vol. 18 No. 1, pp. 44-73. 
QRAM

17,3

Speklé, R.F. (2001), "Explaining management control structure variety: a transaction cost economics perspective', accounting”, Organizations and Society, Vol. 26 Nos 4/5, pp. 419-441.

Suchman, M.C. (1995), "Managing legitimacy: strategic and institutional approaches", Academy of Management Review, Vol. 20 No. 3, pp. 571-610.

Thrane, S. (2007), "The complexity of management accounting change: bifurcation and oscillation in schizophrenic inter-organisational systems", Management Accounting Research, Vol. 18 No. 2, pp. 248-272.

Thrane, S. and Hald, K.S. (2006), "The emergence of boundaries and accounting in supply fields: the dynamics of integration and fragmentation”, Management Accounting Research, Vol. 17 No. 3, pp. 288-314.

Van der Meer-Kooistra, J. and Vosselman, E.G. (2000), "Management control of interfirm transactional relationships: the case of industrial renovation and maintenance', accounting", Organizations and Society, Vol. 25 No. 1, pp. 51-77.

Vélez, M.L., Sánchez, J.M. and Álvarez-Dardet, C. (2008), "Management control systems as interorganizational trust builders in evolving relationships: evidence from a longitudinal case study', accounting", Organizations and Society, Vol. 33 Nos 7/8, pp. 968-994.

Vosselman, E.G. (2002), "Towards horizontal archetypes of management control: a transaction cost economics perspective”, Management Accounting Research, Vol. 13 No. 1, pp. 131-148.

Zahir-Ul-Hassan, M.K., Minnaar, R.A. and Vosselman, E. (2016), "Governance and control as mediating instruments in an inter-firm relationship: towards collaboration or transactions?", Accounting and Business Research, Vol. 46 No. 4, pp. 365-389.

\section{Corresponding author}

Sinikka Lepistö can be contacted at: sinikka.lepisto@oulu.fi 


\begin{tabular}{|c|c|c|c|c|}
\hline Interview date & $\begin{array}{l}\text { Firm(s) } \\
\text { represented }\end{array}$ & Informant(s) & $\begin{array}{l}\text { Duration } \\
\text { (min.) }\end{array}$ & 463 \\
\hline January 2016 & $\begin{array}{l}\text { Pivot, } \\
\text { Electro }\end{array}$ & $\begin{array}{l}\text { Presentation of the firm: led by the management } \\
\text { accounting director and involving managers, team } \\
\text { and process leaders, specialists, and the client's } \\
\text { partnership development director for finance } \\
\text { operations ( } 10 \text { people in all) }\end{array}$ & 153 & \\
\hline January 2016 & Pivot & Process manager & 30 & \\
\hline January 2016 & Pivot & Process specialist & 35 & \\
\hline January 2016 & Pivot & Process manager & 45 & \\
\hline January 2016 & Pivot & Team manager & 57 & \\
\hline January 2016 & Pivot & Process manager & 38 & \\
\hline January 2016 & Pivot & Management accounting director & 41 & \\
\hline January 2016 & Pivot & $\begin{array}{l}\text { Discussion of team promotion and the control and } \\
\text { planning of advertising costs: process manager and } \\
\text { two management accounting specialists }\end{array}$ & 80 & \\
\hline February 2016 & Pivot & Management accounting specialist & 35 & \\
\hline February 2016 & Pivot & Senior process executive & 65 & \\
\hline February 2016 & Pivot & Two management accounting specialists & 130 & \\
\hline February 2016 & Pivot & Manager & 48 & \\
\hline February 2016 & Pivot & Process manager & 41 & \\
\hline February 2016 & Pivot & Team manager and process executive & 80 & \\
\hline February 2016 & Pivot & Process executive & 35 & \\
\hline February 2016 & Pivot & Manager (Lean) & 60 & \\
\hline February 2016 & Pivot & Process manager & 43 & \\
\hline February 2016 & Pivot & Business analyst & 45 & \\
\hline February 2016 & Pivot & Senior business analyst & 73 & \\
\hline May 2016 & Electro & Junior controller & 30 & \\
\hline June 2016 & Electro & Senior controller & 30 & \\
\hline June 2017 & Pivot & Management accounting director & 45 & \\
\hline June 2017 & Electro & $\begin{array}{l}\text { Manager responsible for financial management } \\
\text { systems }\end{array}$ & 27 & \\
\hline August 2017 & Pivot & HR manager and management accounting director & 30 & Table A1. \\
\hline \multicolumn{4}{|c|}{$\begin{array}{l}\text { Note: } 29 \text { informants, in } 23 \text { interviews and at a workshop, for } 21 \mathrm{~h} 36 \mathrm{~min} \text { in total. The organisational } \\
\text { positions in Pivot, from lowest to highest, were the following: Process Executive/Business Analyst, Senior } \\
\text { Process Executive/Senior Business Analyst, Specialist, Process Manager, Deputy Team Manager, } \\
\text { TeamManager, Manager and Director }\end{array}$} & $\begin{array}{l}\text { Details of the } \\
\text { interviews - data } \\
\text { recorded and } \\
\text { transcribed }\end{array}$ \\
\hline
\end{tabular}

\begin{tabular}{llc}
\hline Speaker & Theme & $\begin{array}{c}\text { Duration } \\
\text { (min.) }\end{array}$ \\
\hline Global head of accounting and finance & The BPO relationship and creating value & 9 \\
Global head of accounting and finance & BPO and implementing the Lean approach & 2 \\
Global head of accounting and finance & Defining the customer in BPO & 2 \\
Global head of accounting and finance & Culture change and BPO & 2 \\
\hline
\end{tabular}

Table A2.

Details of the videos transcribed and used for secondary data 